DISTRIBUTION STATEMENT A. Approved for public release; distribution is unlimited.

\title{
Characterizing Surface Transport Barriers in the South China Sea
}

\author{
Thomas Peacock \\ Mechanical Engineering, MIT \\ Cambridge, MA 02139 \\ phone: (617) 258-0736 fax: (617) 258-8742 email: tomp@mit.edu \\ Award Number: N000141210665 \\ http://web.mit.ed/endlab
}

\section{LONG-TERM GOALS}

The long term goal of this project is to advance the state of the art in mathematical methods for detecting key transport structures in velocity field data sets for spatially complex, time-dependent, ocean surface flows. Such transport structures are typically not inherently obvious in snapshots of the Eulerian velocity field and require analysis methods with foundations in Lagrangian flow transport. Within the context of this DRI, a long term goal is to improve understanding of the formation and location of submesoscale fronts in the South China Sea (SCS).

\section{OBJECTIVES}

The scientific objective is to test and develop novel methods, with a focus of the approach of Lagrangian Coherent Structures (LCSs). We seek to demonstrate the utility and robustness of the method through application to ocean data sets pertaining the SCS, and more specifically the region immediately to the southwest of Taiwan. Furthermore, we seek to directly apply these methods to data sets from HF radar.

\section{APPROACH}

The approach involves using MATLAB and $\mathrm{C}++$ based software to perform processing of the data sets. The code has been developed by a graduate student (Allshouse) and a postdoc (Leclair). Data sets for analysis are provided by other members of the DRI, such as John Wilkin, and HF radar data from the Taiwanese TORI network.

\section{WORK COMPLETED}

There have been substantial developments of the computational code. First, and foremost, the code has been reconfigured to work in arbitary curvilinear coordinates. This has several benefits. For investigations of large scale ocean domains the LCS code can work directly with the girdded information provided by a numerical model and no longer approximated the domain by projection on a rectilinear grid. This also reduces errors introduced into the trajectories of advected material. Finally, in these native coordinates the LCS code is more capable of handling the complex shapes of coastlines, which is an issue that is known to introduce suprious LCS. The second advance of the code is that a scheme has been introduce to ensure conservation of flux through a grid cell, so that there is no 


\section{Report Documentation Page}

Form Approved

OMB No. 0704-0188

Public reporting burden for the collection of information is estimated to average 1 hour per response, including the time for reviewing instructions, searching existing data sources, gathering and maintaining the data needed, and completing and reviewing the collection of information. Send comments regarding this burden estimate or any other aspect of this collection of information,

including suggestions for reducing this burden, to Washington Headquarters Services, Directorate for Information Operations and Reports, 1215 Jefferson Davis Highway, Suite 1204, Arlington

VA 22202-4302. Respondents should be aware that notwithstanding any other provision of law, no person shall be subject to a penalty for failing to comply with a collection of information if it

does not display a currently valid OMB control number.

1. REPORT DATE

30 SEP 2014

4. TITLE AND SUBTITLE

Characterizing Surface Transport Barriers in the South China Sea

6. $\operatorname{AUTHOR}(\mathrm{S})$

7. PERFORMING ORGANIZATION NAME(S) AND ADDRESS(ES)

Massachusetts Institute of Technology,Department of Mechanical

Engineering,Cambridge,MA,02139

9. SPONSORING/MONITORING AGENCY NAME(S) AND ADDRESS(ES)

3. DATES COVERED

00-00-2014 to 00-00-2014

5a. CONTRACT NUMBER

5b. GRANT NUMBER

5c. PROGRAM ELEMENT NUMBER

5d. PROJECT NUMBER

5e. TASK NUMBER

5f. WORK UNIT NUMBER

8. PERFORMING ORGANIZATION

REPORT NUMBER

10. SPONSOR/MONITOR'S ACRONYM(S)

11. SPONSOR/MONITOR'S REPORT

$\operatorname{NUMBER}(S)$

12. DISTRIBUTION/AVAILABILITY STATEMENT

Approved for public release; distribution unlimited

13. SUPPLEMENTARY NOTES

14. ABSTRACT

15. SUBJECT TERMS

16. SECURITY CLASSIFICATION OF:

a. REPORT

unclassified b. ABSTRACT

unclassified c. THIS PAGE

unclassified
17. LIMITATION OF ABSTRACT

Same as

Report (SAR)
18. NUMBER 19a. NAME OF

OF PAGES RESPONSIBLE PERSON

3 
numerical introduction or extraction of volume, again creating spurious LCS. Finally, the code has been configured to run on a GPU so that it runs considerably faster.

In February 2014, the postdoc working on this project participated in the South China Sea field experiments and also visited TORI. The HF radar data from TORI was processed in near real time and supplied to the science team in order to facilitate their search for submesoscale fronts in the region.

\section{RESULTS}

The LCS processing during the SCS cruise was able to detect Lagrangian features characteristic of fronts and relay this information to cruise. An example of this processing applied to a TORI data set is presented in figure 1. There were challenges in the quality of the data due to the time-varying technical issues with the domain of coverage of the HF radar. More work needs to be done to determine if the LCS detected in the HF radar data truly corresponded to ocean fronts detected by the science team.

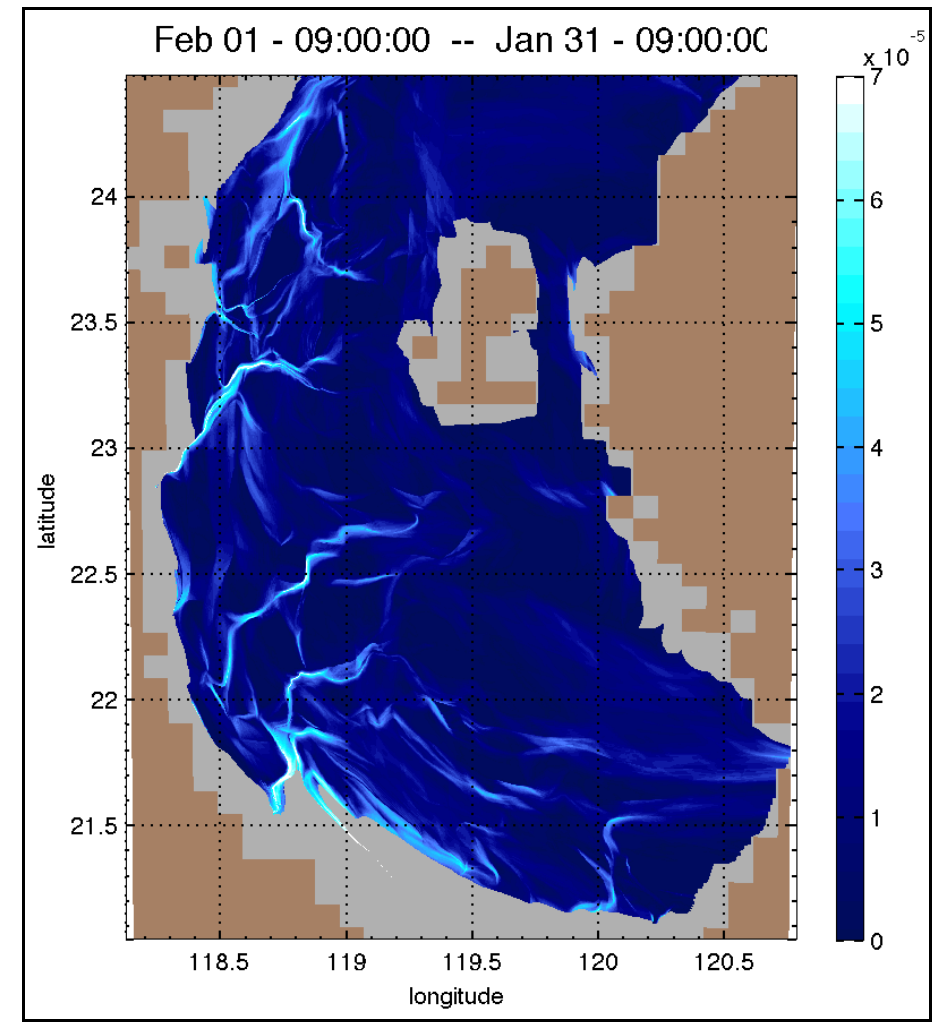

Figure 1: Attracting LCS for a 12 hour time window in February 2014 using TORI HF radar data. Several attracting features are observable and are candidates for surface signatures of ocean fronts.

We have also investigated the application of the methods to the study of regions containing coral reefs, which could be applicable to the vicinity of Dongsha Island, for example. Figure 2 shows the connectivity of a coral reef system for a 12 hour time window calculated using the LCS approach. 


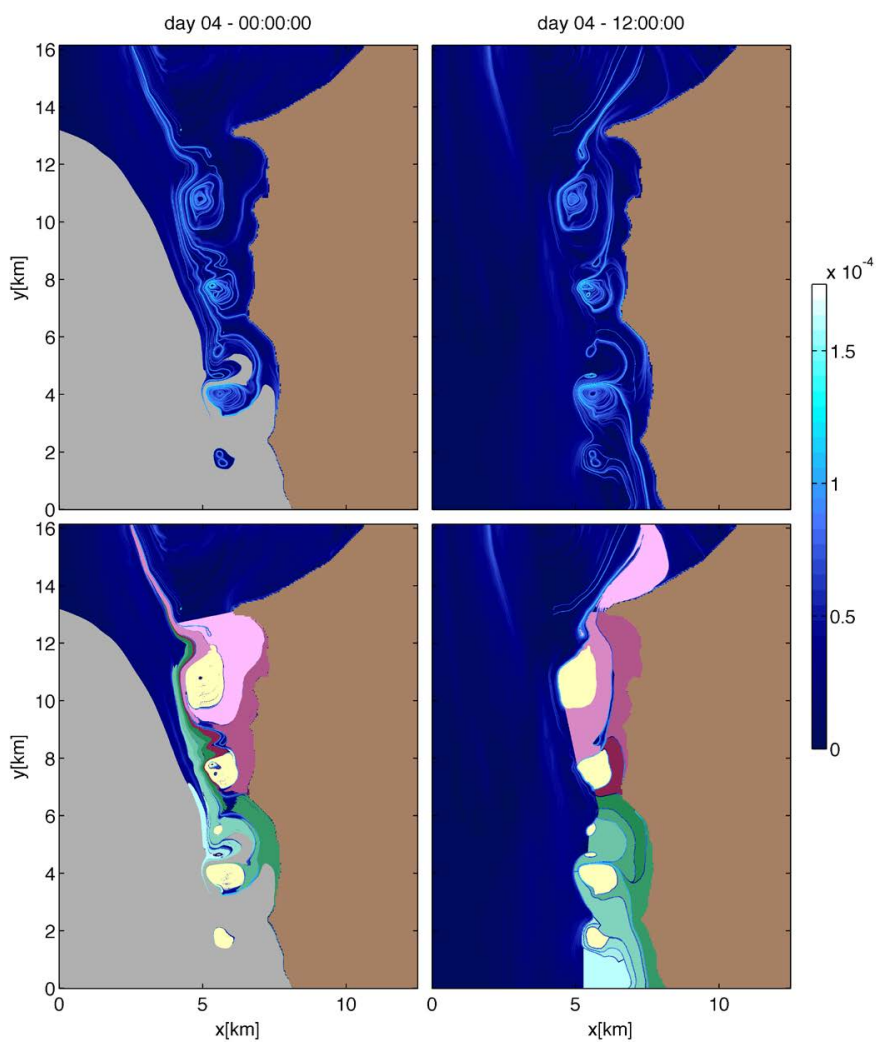

Figure 2: (top left and right) Repelling and attracting LCS for a coral reef system (off the west coast of Australia) over a 12 hour time window. (bottom left and right) The flow domain is organized into three components: offshore vortices that trap fluid (yellow), northward advected material (magenta) and southward advected material (green).

\section{IMPACT/APPLICATIONS}

The analysis during the SCS experiment provided valuable guidance for the real-time decision making of the science team. The improved computational methods make the LCS approach ever more computationally efficient and robust, further advocating its real world applicability. A major LCS workshop was held at the Banff International Research station. 